\title{
Phenotypic Assay Leads to Discovery of Mitophagy Inducers with Therapeutic Potential for Parkinson's Disease
}

\author{
Inés Maestro, Laura R. de la Ballina, Anne Simonsen, Patricia Boya,* and Ana Martinez* \\ Cite This: ACS Chem. Neurosci. 2021, 12, 4512-4523 \\ Read Online
}

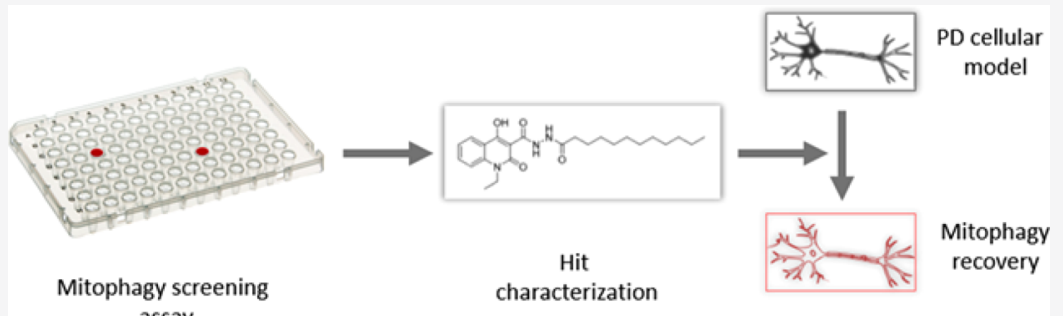

ABSTRACT: Mitophagy, the selective degradation of mitochondria by autophagy, involved in important physiological processes and defects in pathways has been reported in pathological conditions, such as neurodegeneration. Thus, mitophagy is an interesting target for drug discovery programs. In this investigation, we used robust phenotypic assay to screen a set of 50 small heterocyclic compounds to identify inducers of mitophagy. We identified two compounds, VP07 and JAR1.39, that induce Parkin-dependent mitophagy. Based on structure-activity relationship studies, we proposed the ability of the compounds to act as light chain 3 (LC3) interactors, similar to cardiolipin or ceramide, triggering mitophagy via Pink1/Parkin. Finally, we show promising therapeutic applicability in a cellular model of Parkinson's disease.

KEYWORDS: mitophagy, phenotypic assay, drug discovery, mitophagy inducers, Parkinson's disease

\section{INTRODUCTION}

Mitophagy refers to the selective degradation of mitochondria through autophagy. This process involves the sequestration of mitochondria into double membrane vesicles called autophagosomes, which will fuse with lysosomes, where mitochondria will be degraded. ${ }^{1}$ Mitophagy can be induced by different stimuli, and several mechanistically different mitophagy pathways have been described, with the Pink1/Parkin-dependent pathway being the one most studied. Pink1 is a kinase that is constitutively cleaved in the mitochondria. Upon mitochondrial membrane depolarization, the mitochondrial import of Pink 1 is blocked, leading to its localization in the outer mitochondrial membrane (OMM), where it phosphorylates ubiquitin residues on OMM proteins and facilitates the recruitment of Parkin. When Parkin, an E3 ubiquitin ligase, is active, it further ubiquitinates OMM proteins or pre-ubiquitinated chains, which will be phosphorylated by Pink1. This stimulates the recruitment of autophagy receptors with a ubiquitin-binding domain that also has a microtubule-associated protein 1A/1B-light chain 3 (LC3) interacting region, which binds autophagosomes. In addition, the adaptor called nuclear dot $52 \mathrm{kD}$ protein (NDP52) binds to the FAK kinase interacting protein of $200 \mathrm{kD}$ (FIP200), recruiting the UNC-51 like autophagy activating kinase 1 (ULK1) complex. ${ }^{2}$ All these events foster the formation of mitophagosomes. ${ }^{3,4}$

Mitophagy has an important cellular quality control function, and it is also involved in other important physiological processes, such as cell differentiation, cell death, and immune response. ${ }^{5}$ Furthermore, neurons are postmitotic cells, indicating that they cannot get rid of defective mitochondria by cell division. Therefore, they rely on mitophagy/mitochondrial biogenesis to maintain a healthy pool of mitochondria to sustain cellular homeostasis. ${ }^{6}$ This fact highlights the importance of mitophagy to prevent conditions such as neurodegeneration or ageing. Reduced mitophagy has been reported not only in aged animals but also in mice models of Huntington's disease. ${ }^{7}$ Mitophagy defects have also been described in preclinical models of Alzheimer's disease $(\mathrm{AD})$, postmortem tissue of $\mathrm{AD}$ patients, and in the central nervous system (CNS) and platelets of patients with Parkinson's disease (PD). Similarly, swollen and dysfunctional mitochondria were found in the motor neurons of patients with amyotrophic lateral sclerosis (ALS). ${ }^{8,9}$

These data highlight the importance of mitophagy in these severe pathological conditions. ${ }^{10}$ The need for new chemical

Received: August 7, 2021

Accepted: November 4, 2021

Published: November 30, 2021

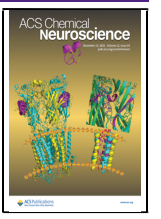


A)
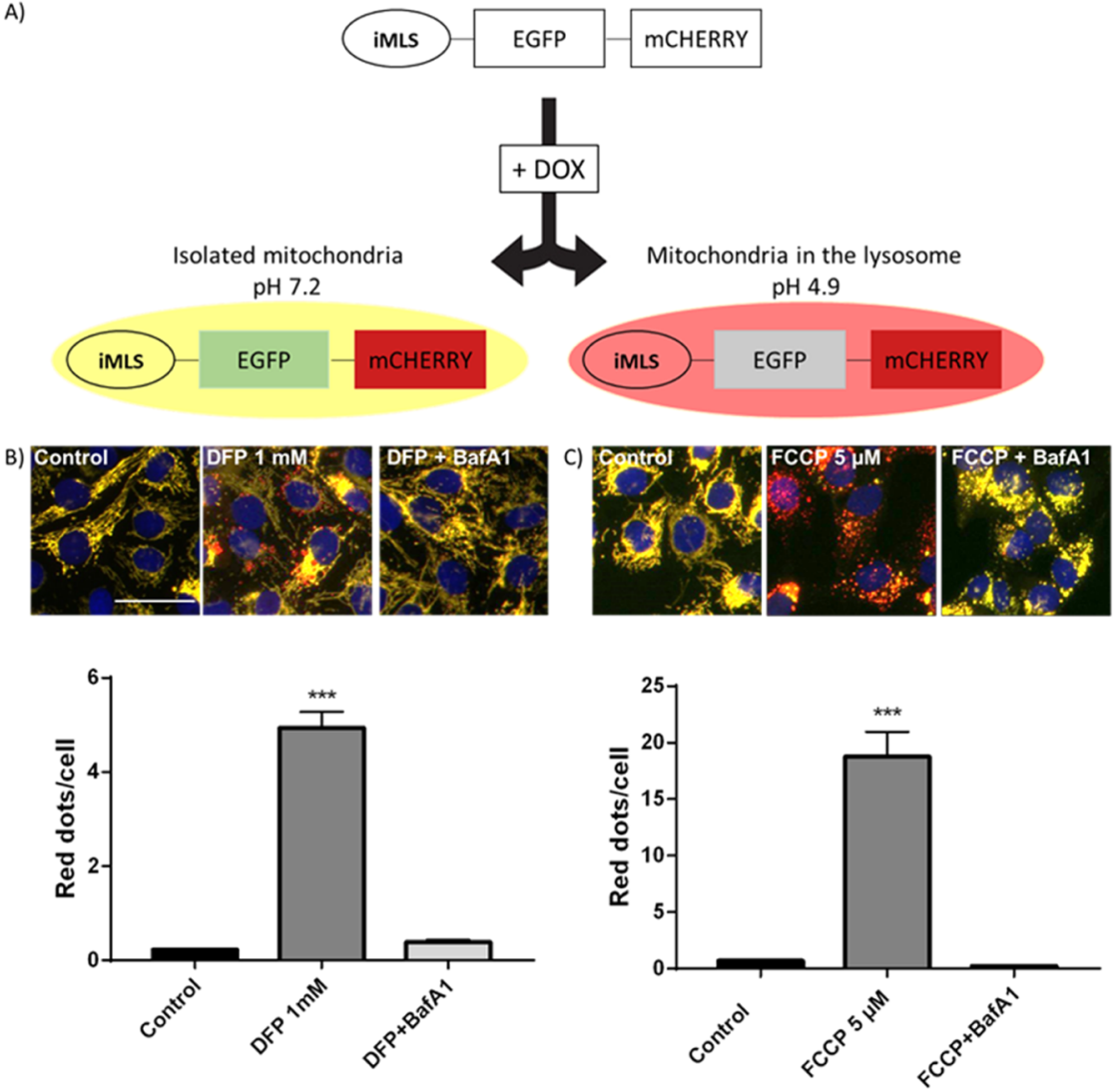

Figure 1. Description of the iMLS reporter and assay setup. (A) Mitophagy reporter description. (B) U2OS-iMLS and (C) U2OS-iMLS cells expressing Parkin were treated with the controls for $24 \mathrm{~h}$. BafAl was added for the last $2 \mathrm{~h}$. Data represent the mean \pm SEM of three experiments. Significance was determined by one-way ANOVA, followed by Dunnett's multiple comparison test to control, where ***p $=0.0001$. Scale bar $=50 \mu \mathrm{m}$.

tools that allow the molecular study of mitophagy in health and its modulation in disease is a great challenge for the scientific community. The lack of techniques to quantify mitophagy flux together with its very dynamic process has hindered the identification of small molecules for mitophagy modulation. Currently, we can count on several methods such as flow cytometry $^{11}$ or several fluorescent reporters by microscopy ${ }^{12}$ that can be used in different studies.

In this investigation, we performed phenotypic screening to identify novel mitophagy enhancers using U2OS cells expressing a mitophagy reporter. We followed a reverse chemical genetic approach using a set of 50 compounds preselected from our inhouse chemical library, called the Medicinal and Biological Chemical (MBC) library, ${ }^{13}$ which is based on chemical diversity. Upon screening for effects on mitophagy, two hits were identified as mitophagy inducers and were further characterized in ARPE-19 cells, a spontaneously immortalized cell line of human retinal pigment epithelium, to determine their mechanisms of action, identify their molecular potential targets, and explore their therapeutic applications. These two small molecules, which have been reported to be brain permeable, ${ }^{14}$ may serve as versatile chemical tools for further mitophagy studies in CNS pathologies in both cellular and in vivo models.

\section{RESULTS AND DISCUSSION}

Phenotypic Mitophagy Assay Optimization. To screen for regulators of mitophagy, we took advantage of image-based assay using a stable U2OS cell line with doxycycline-inducible expression of the double-tagged NIPSNAP internal mitochon- drial localization signal (iMLS, NIPSNAP $1_{1-53}$-EGFPmCherrry) previously described as a mitophagy reporter. ${ }^{15}$ As U2OS cells do not express Parkin, ${ }^{16}$ we also used U2OS-iMLS cells transduced with a lentiviral particle expressing Parkin (U2OS-iMLS-Parkin). With this method, we assessed the effects of modulators on both Parkin-dependent and independent mitophagy. Similar to other tandem reporters, iMLS is $\mathrm{pH}$ sensitive. When mitochondria are in the cytosol $(\mathrm{pH} \sim 7.2)$, the reporter is seen in yellow as a combination of mCherry and green fluorescent protein (EGFP). However, when the mitochondria are inside the acidic compartments $(\mathrm{pH} \sim 4.5-$ 5 ), the reporter is seen as red only due to the EGFP quenching at a low $\mathrm{pH}$ value. To induce expression of the mitophagy reporter, the U2OS-iMLS cells were treated with doxycycline for $24 \mathrm{~h}$ (Figure 1A).

Several controls were used to ensure the correct functioning of the assay. The vehicle in which the compounds were dissolved (0.1\% DMSO) was used as a negative control. Deferiprone (DFP, $1 \mathrm{mM}$ ), an iron chelator, was used as a positive control in the U2OS-iMLS cells, while the mitochondrial uncoupler carbonilcianuro- $p$-trifluorometoxifenilhidrazona (FCCP, 5 $\mu \mathrm{M})$ was used as a positive control for the U2OS-iMLS -Parkin cells. ${ }^{17}$ Finally, the V-ATPase inhibitor bafilomycin A1 (BafA1) was added to both cell lines during the last $2 \mathrm{~h}$ of treatment to increase the $\mathrm{pH}$ and restore the EGFP signal in the acidic compartments. ${ }^{18}$ The number of red-only structures per cell was monitored as a readout of the iMLS reporter degradation and therefore was used to quantify mitophagy in the cells.

As expected, both positive controls, DFP (Figure 1B) and FCCP (Figure 1C) significantly induced mitophagy, while no 

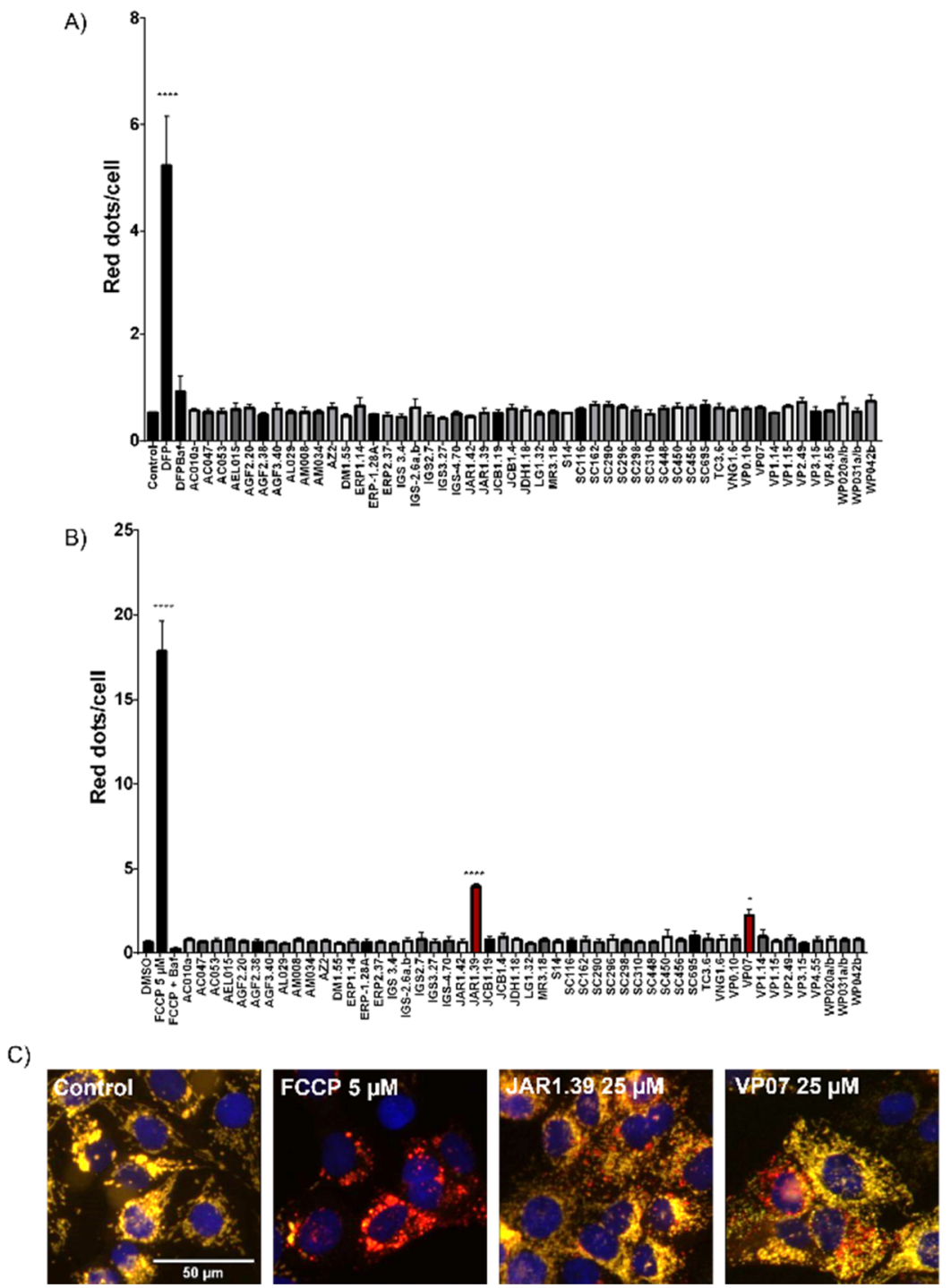

Figure 2. JAR1.39 and VP07 induce mitophagy in Parkin-expressing U2OS-iMLS cells. (A) U2OS-iMLS and (B) U2OS-iMLS-Parkin cells (50,000 cells $/ \mathrm{mL}$ ) were treated with compounds preselected from the MBC library at $25 \mu \mathrm{M}$ for $24 \mathrm{~h}$ prior to high content imaging and image analysis. (C) Image representation of Parkin-expressing U2OS-iMLS treated with FCCP, JAR1.39, and VP07. Data represent the mean \pm SEM of three independent experiments. Significance was determined by one-way ANOVA, followed by Dunnett's multiple comparison test to control, where $* * * * p<0.0001$ and $* * * p<0.0005$. Scale bar $=50 \mu \mathrm{m}$.

red-only puncta were seen in cells treated with the negative control. The final addition of BafAl to both positive inducers completely restored the network, blocking the mitochondrial degradation (Figure 1B,C).

Discovery of Mitophagy Inducers in U2OS-iMLS Cells. We then used the abovementioned optimized assays to evaluate the efficacy of a set of small heterocyclic compounds to induce mitophagy (Table S1). Both cell lines were treated with a total of 50 compounds (used at $25 \mu \mathrm{M}$ for $24 \mathrm{~h}$ ) preselected from the MBC library. The selection was based on the chemical structure and diversity of biological activities. Therefore, we chose compounds representing more than 20 diverse heterocyclic scaffolds (Table S1) and several diverse enzymatic activities such as kinase or phosphodiesterase inhibitors, among others. None of the tested small molecules induced mitophagy in the U2OS-iMLS cells (Figure 2A); however, two compounds, identified as JAR1.39 and VP07, were found to induce mitophagy in the U2OS-iMLS-Parkin cells (Figure 2B,C). Both compounds induced a mitochondrial morphology change from a filament-shaped network to a more round-shaped network, similar to FCCP treatment, suggestive of mitochondria fission (Figure 2C). However, unlike FCCP treated cells, in which almost the entire mitochondrial network was degraded, treatment with JAR1.39 and VP07 did not result in massive mitophagy, which is preferable for a compound. Thus, both JAR1.39 and VP07 were selected for further characterization.

Hit Characterization in Parkin-Expressing U2OS-iMLS

Cells. After the first analysis, we characterized the dose-response relationship of JAR1.39 and VP07. To achieve this, cells were treated with increasing concentrations of the compounds (from 1.56 to $25 \mu \mathrm{M}$ ) for $24 \mathrm{~h}$, and mitophagy levels were determined by the quantification of red-only puncta in the U2OS-iMLSParkin cells. As expected, JAR1.39-induced mitophagy occurred significantly at the highest concentration while a dosedependent response trend was observed (Figure 3B,D). Interestingly, this dose-response relationship was also related to mitochondrial fission (Figure $3 \mathrm{E}$ ). Using image analysis by CellProfiler, ${ }^{19}$ we measured the mean area of the segmented 
A)

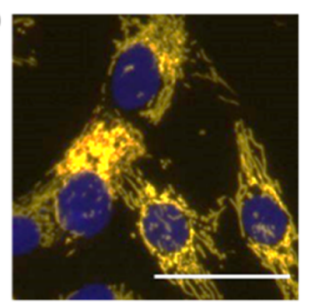

B)
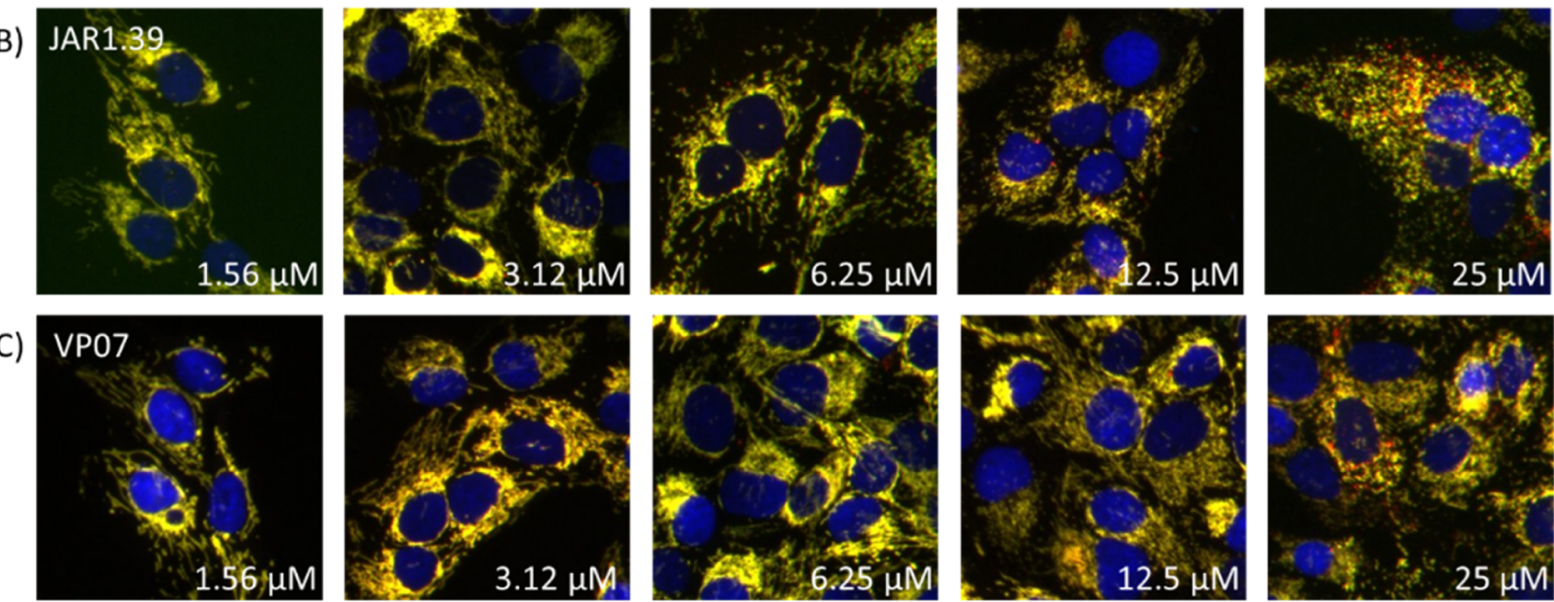

D)

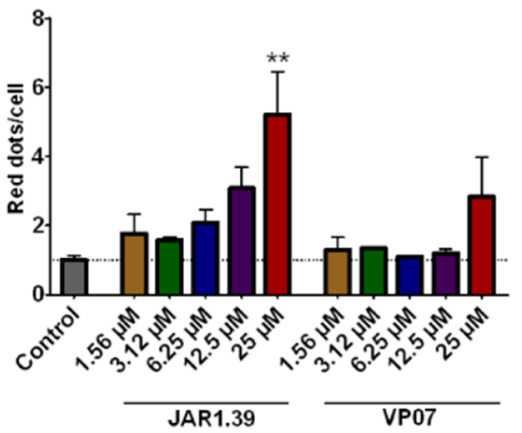

E)

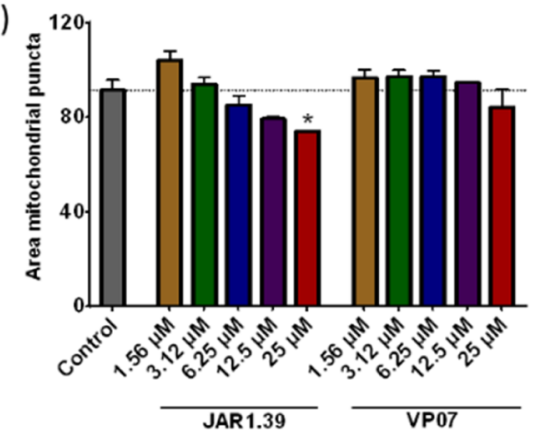

Figure 3. Hit characterization in U2OS-iMLS transduced with Parkin. 50,000 cells/mL were treated with (A) control or increasing doses of (B) JAR1.39 and (C) VP07 for $24 \mathrm{~h}$. Quantification of (D) mitophagy flux (red dots only per cell) and (E) mitochondrial fragmentation (area mitochondrial puncta). Data represent mean \pm SD of two independent experiments. Data from (D) were normalized to control. Significance was determined by one-way ANOVA, followed by Dunnett's multiple comparison test to control, where $* * p<0.01$ and $* p<0.05$. Scale bar $=50 \mu$ m.

mitochondrial network (see Experimental Part) after drug treatment and observed a clear reduction after treatment with JAR1.39 at the highest concentration (Figure 3E).

For the cells treated with VP07, we again observed an increase in red dots compared to the control cells (Figure 3C,D). As with JAR1.39, mitochondrial fragmentation was determined and a trend in reduction of the mitochondrial network area was observed when mitophagy was induced (Figure 3E).

Due to these results, we decided to continue working with these compounds at $25 \mu \mathrm{M}$ for $24 \mathrm{~h}$.

To further confirm the ability of JAR1.39 and VP07 to induce mitophagy, three different studies were performed. First, the levels of two mitochondrial proteins, TOMM20 (in the OMM) and TIMM23 (in the inner mitochondrial membrane) were measured by western blot analysis. As shown in Figure 4A, the levels of both proteins were reduced upon treatment with the positive control, FCCP, and the discovered hits, pointing to a mitochondrial mass reduction as mitophagy increased.

Second, mitophagy induction could be determined by studying the enzymatic activity of the mitochondrial matrix protein citrate synthase. This enzyme participates in Kreb's cycle, and its activity could be related to the number of mitochondria in a sample. For this reason, the cells were treated with VP07 and JAR1.39, showing a clear reduction in the activity of the enzyme compared to control cells, confirming mitochondrial degradation by increased mitophagy (Figure 4B).

Third, the U2OS cells expressing Parkin were immunostained for LC3 to study the recruitment of LC3 to the mitochondria upon mitophagy induction with the hits. For this purpose, only the $\mathrm{mCherry}$ fluorophore from the iMLS reporter was imaged as a mitochondrial marker. An increase in both LC3 punctae and LC3 colocalization with mitochondria was observed after treatment with the compounds compared to the control (Figure 4C).

Hit Confirmation in ARPE-19 MitoQC Cells. We then validated the mitophagy-inducing capacity of both compounds using ARPE-19 cells, a human retinal pigment epithelial cell line that constitutively expresses Parkin. ${ }^{20}$ We also used another mitophagy reporter, mCherry-GFP-FIS1 $1_{101-152}$ (known as MitoQC), based on the fusion of mCherry-GFP to the OMM protein FIS $1 .{ }^{21}$ This differs from the iMLS reporter, which contains a portion of NIPSNAP1, a matrix protein. ${ }^{15}$ 
A)
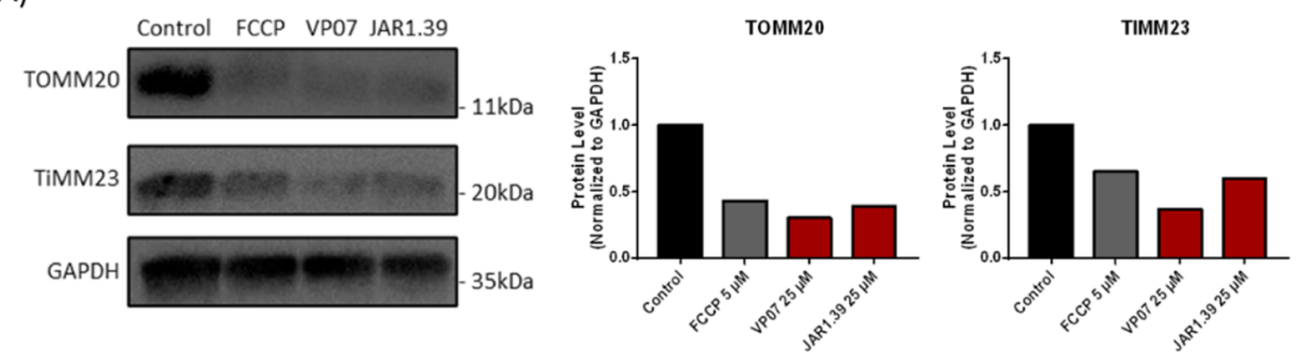

B)

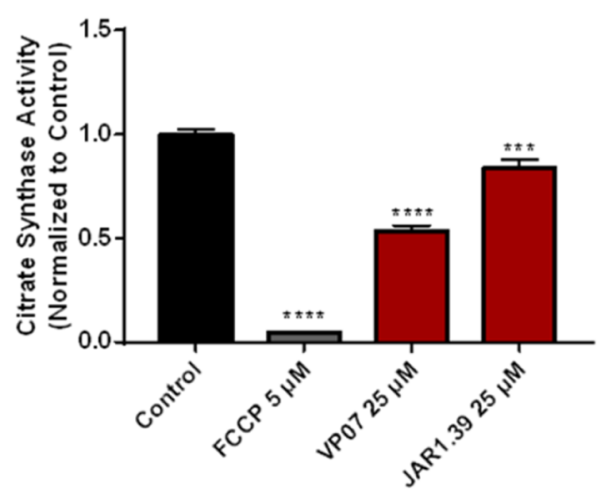

C)
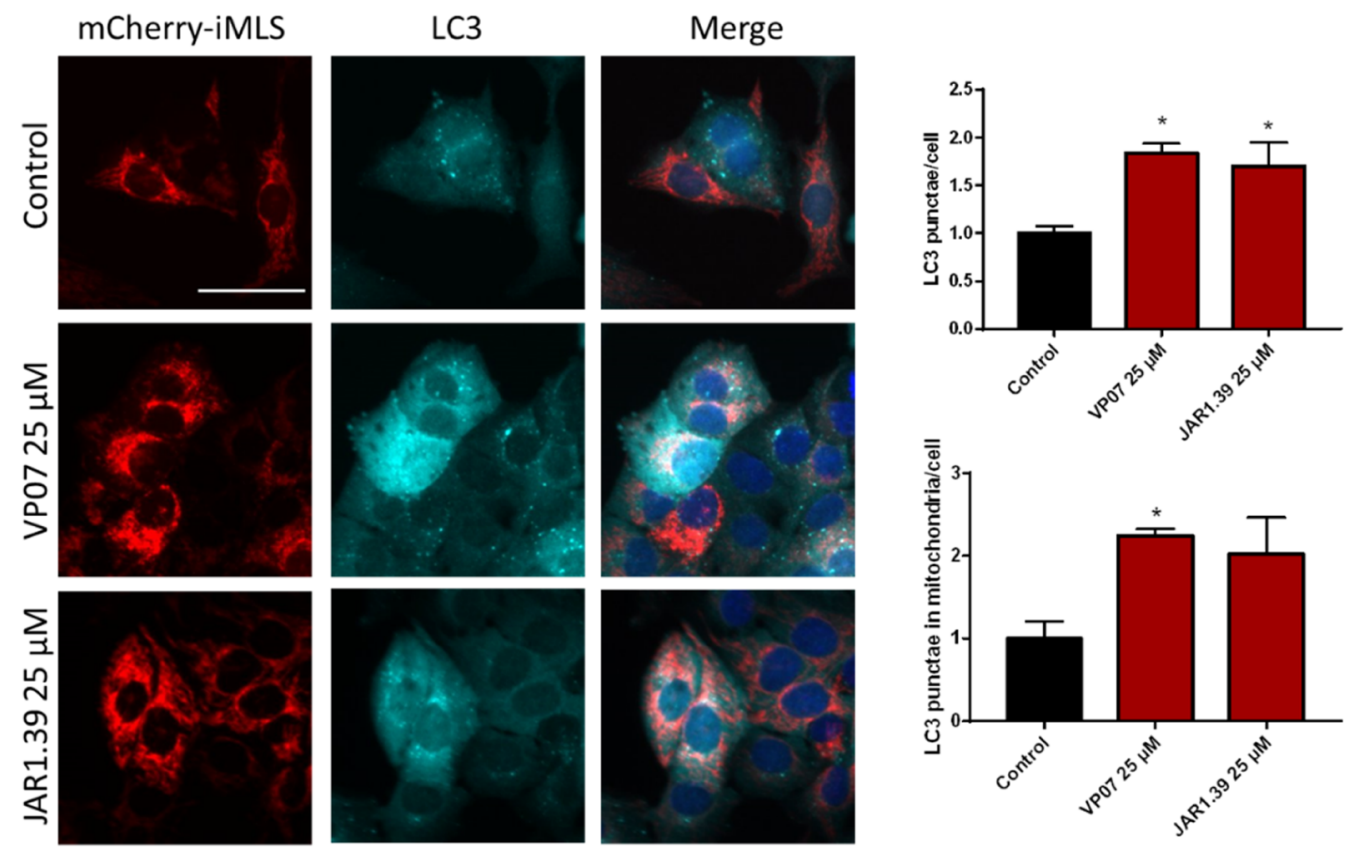

Figure 4. Mitophagy increase by VP07 and JAR1.29 in U2OS-iMLS cells transduced with Parkin. (A) Western blot of mitochondrial proteins treated with VP07 and JAR1.39 at $25 \mu \mathrm{M}$ for $24 \mathrm{~h}$. (B) Citrate synthase activity after the treatment with VP07 at $25 \mu \mathrm{M}$ for $24 \mathrm{~h}$. (C) Immunostaining for LC3 after the treatment with VP07 and JAR1.39 at $25 \mu \mathrm{M}$ for $24 \mathrm{~h}$. Data were normalized to control. Graphs represent (A) one single experiment, (B) mean \pm SD of three replicates from one experiment, and (C) mean \pm SEM of three independent experiments. Significance was determined by one-way ANOVA, followed by Dunnett's multiple comparison test to control, where $* * * * p<0.0001, * * * p<0.0005$, and $* p<0.05$. Scale bar $=50 \mu \mathrm{m}$.

The ability of the two identified compounds, JAR1.39 and VP07, to induce mitophagy and mitochondrial fission was validated in ARPE-19 MitoQC cells, as shown in Figure 5. Our results corroborated the efficacy of JAR1.39 and VP07 to induce mitophagy in different cell lines, using two different mitophagy reporter systems. In addition, our data showed that in the ARPE-
19 cell line, VP07 has a stronger mitophagy-inducing effect than JAR1.39 at the same dose.

Untangling the Potential Mechanism of Action. Biological Activity-Based Decoding. JAR1.39 and VP07 were previously synthetized in a medicinal chemistry program designed to discover allosteric brain permeable glycogen synthase kinase 3 (GSK3) inhibitors and were included in the 

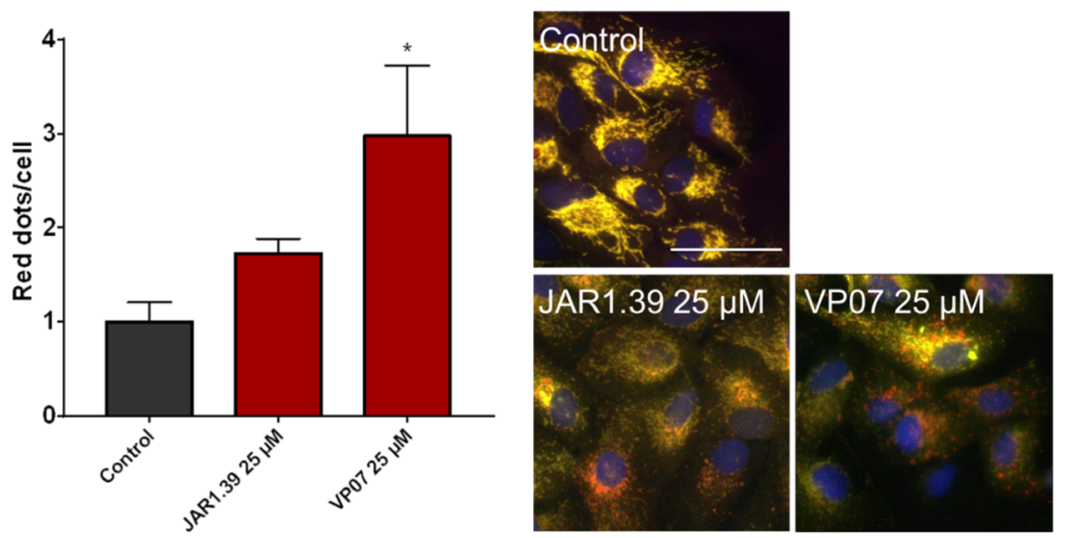

Figure 5. Validation of mitophagy-inducing capacity of the compounds in the ARPE-19 MitoQC cell line. 50,000 cells/mL were treated with the hit compounds at $25 \mu \mathrm{M}$ for $24 \mathrm{~h}$. Values were normalized to control (DMSO 0.1\%). Data represent the mean \pm SEM of three experiments. Significance was determined by one-way ANOVA, followed by Dunnett's multiple comparison test to control, where* $p<0.05$. Scale bar $=50 \mu \mathrm{m}$.

MBC library. ${ }^{14}$ GSK3 is a kinase upregulated in several neurodegenerative conditions and has been shown to be involved in different cellular key survival/death processes such as autophagy, inflammation, and oxidative stress. ${ }^{22,23}$ Its role in mitophagy and mitochondrial quality control has been recently described. ${ }^{24,25}$ Therefore, GSK3 was a likely candidate to be involved in the mechanism by which these two hits induced mitophagy. Following a chemical genetic approach ${ }^{26}$ and using our diverse collection of GSK3 inhibitors as chemical probes, we showed that mitophagy increases produced by JAR1.39 and VP07 were not likely associated with GSK3 inhibition. We have observed how diverse chemical structures, such as iminothiadiazoles $^{27}$ or thiadiazolidindiones ${ }^{28}$ with different binding modes to GSK3 and included in the initial set of compounds used for mitophagy screening, were not able to induce mitophagy (Figure 2 and Table 1). As all these small molecules, named VP1.14, VP1.15, VP3.15, and VP4.55 (Table 1), shared the property of inhibiting GSK3, we conclude that it is plausible that JAR1.39 and VP07 induce mitophagy independent of their GSK3 inhibitory activity.

Chemical Structure-Based Deciphering: Structure-Activity Relationship Studies. We next explored the mechanism of action by chemical structure-activity relationship (SAR) studies. As previously stated, JAR1.39 and VP07 were synthesized in a medicinal chemistry project to target GSK3 allosterically. Based on hydrazide derivatives of a quinoline scaffold, new compounds were developed. ${ }^{14}$

To determine if the mitophagy modulation effects of JAR1.39 and VP07 were related to their chemical structure, we evaluated a set of 34 hydrazide derivatives containing a quinolone scaffold in our mitophagy assay in ARPE-19 MitoQC cells (Figure 6 and Table 2).

Several of these new compounds behave as mitophagy enhancers. The compounds were classified based on their degree of biological activity. Interestingly, we can establish a clear relationship between their potency to induce mitophagy and chemical structure. Specifically, the nature of the substituent in position $\mathrm{R}_{4}$ (Table 2), aromatic or aliphatic, is of utmost importance for mitophagy induction. When $\mathrm{R}_{4}$ had an aromatic group, like in the case of phenyl, benzyl, or dimethylene heteroaryl fragments (derivatives VP3.34, VP3.38, VP3.63, VP3.59, and VP3.52; Figure 6 and Table 2), the compounds did not induce mitophagy. In contrast, when the $\mathrm{R}_{4}$ substituent was an aliphatic element, we observed three different situations. If
Table 1. Chemical Structures of GSK3 Inhibitors Included in the Screening Mitophagy Phase and Their $\mathrm{IC}_{50}$ Values

\begin{tabular}{|c|c|c|c|}
\hline $\begin{array}{c}\text { Compound } \\
\text { ID }\end{array}$ & $\begin{array}{c}\text { GSK3 } \\
\mathrm{IC}_{50}(\mu \mathrm{M})\end{array}$ & Celluar assay \\
\hline JAR1.39 & Chemical structure & 2.01 \\
\hline VP07 & & \\
\hline VP1.14 & & \\
\hline VP1.15 & & \\
\hline VP4.55 & \\
\hline
\end{tabular}

the alkylic moiety was very short such as a methyl group (VP3.37), mitophagy was not induced. However, when $\mathrm{R}_{4}$ was an aliphatic chain, its length became a key chemical feature for biological activity. Two situations are distinguishable in regard to short $\left(\mathrm{C}_{7} \mathrm{H}_{15}\right)$ and long $\left(\mathrm{C}_{11} \mathrm{H}_{23}\right)$ aliphatic chains. When comparing pairs of compounds with the same substituents in $\mathrm{R}_{1}$, $\mathrm{R}_{2}$, and $\mathrm{R}_{3}$ and a different length of the aliphatic chain in $\mathrm{R}_{4}$, only compounds with longer aliphatic chains in $\mathrm{R}_{4}$ induced mitophagy (see VP07 vs VP3.58, Figure 6).

Interestingly, JAR2.16, which also had a longer aliphatic chain with 11 carbon atoms, induced mitophagy as expected but did not inhibit GSK3 $\left(\mathrm{IC}_{50}>20 \mu \mathrm{M}\right) .{ }^{14}$ This data confirmed the 


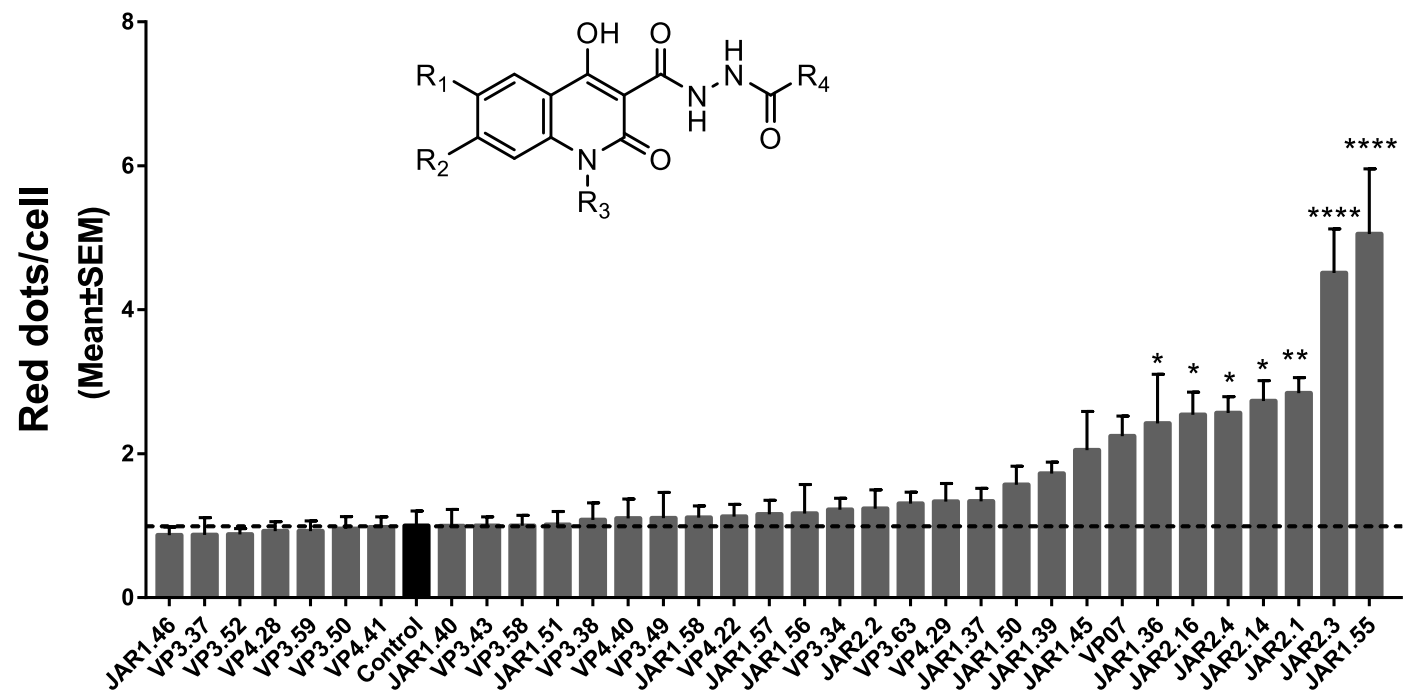

Figure 6. General chemical structure of hydrazide derivatives of quinolines and evaluation of mitophagy induction of several related compounds. The ARPE-19 MitoQC cells $(50,000$ cells $/ \mathrm{mL})$ were treated at $25 \mu \mathrm{M}$ for $24 \mathrm{~h}$. Data represent the mean \pm SEM of three experiments. Values were normalized to control. Significance was determined by one-way ANOVA, followed by Dunnett's multiple comparison test to control, where $* p<0.05$, $* * p<0,005$, and $* * * * p<0.0001$.

Table 2. Structure of Hydrazide Derivatives of the Quinoline Family ${ }^{a}$

\begin{tabular}{|c|c|c|c|c|}
\hline $\begin{array}{l}\text { Comp } \\
\text { ID }\end{array}$ & $\mathbf{R}_{1}$ & $\mathbf{R}_{\mathbf{2}}$ & $\mathbf{R}_{\mathbf{3}}$ & $\mathbf{R}_{\mathbf{4}}$ \\
\hline JAR1.55 & $\mathrm{H}$ & $\mathrm{Cl}$ & Et & $-\mathrm{C}_{11} \mathrm{H}_{23}$ \\
\hline JAR2.3 & $\mathrm{H}$ & $\mathrm{Cl}$ & $-\mathrm{CH}_{2} \mathrm{Ph}$ & $-\mathrm{C}_{11} \mathrm{H}_{23}$ \\
\hline JAR2.1 & $\mathrm{H}$ & $\mathrm{H}$ & & $-\mathrm{C}_{11} \mathrm{H}_{23}$ \\
\hline JAR2.14 & $\mathrm{H}$ & $\mathrm{H}$ & & $-\mathrm{C}_{11} \mathrm{H}_{23}$ \\
\hline JAR2.4 & $\mathrm{H}$ & $\mathrm{Cl}$ & $-\mathrm{CH}_{2} \mathrm{Ph}$ & $-\mathrm{C}_{7} \mathrm{H}_{15}$ \\
\hline JAR2.16 & $\mathrm{H}$ & $\mathrm{H}$ & $-\mathrm{Pr}^{\mathrm{i}}$ & $-\mathrm{C}_{11} \mathrm{H}_{23}$ \\
\hline JAR1.36 & $\mathrm{Cl}$ & $\mathrm{H}$ & Et & $-\mathrm{C}_{11} \mathrm{H}_{23}$ \\
\hline JAR1.45 & $\mathrm{Cl}$ & $\mathrm{H}$ & $\mathrm{Me}$ & $-\mathrm{C}_{11} \mathrm{H}_{23}$ \\
\hline JAR1.39 & $\mathrm{Br}$ & $\mathrm{H}$ & Et & $-\mathrm{C}_{11} \mathrm{H}_{23}$ \\
\hline JAR1.50 & $\mathrm{Br}$ & $\mathrm{H}$ & $\mathrm{Me}$ & $-\mathrm{C}_{11} \mathrm{H}_{23}$ \\
\hline VP07 & $\mathrm{H}$ & $\mathrm{H}$ & Et & $-\mathrm{C}_{11} \mathrm{H}_{23}$ \\
\hline JAR1.37 & $\mathrm{Cl}$ & $\mathrm{H}$ & Et & $-\mathrm{C}_{7} \mathrm{H}_{15}$ \\
\hline VP4.29 & $\mathrm{F}$ & $\mathrm{H}$ & $\mathrm{H}$ & $-\mathrm{C}_{11} \mathrm{H}_{23}$ \\
\hline VP3.63 & $\mathrm{H}$ & $\mathrm{H}$ & Et & \\
\hline JAR2.2 & $\mathrm{H}$ & $\mathrm{H}$ & & $-\mathrm{C}_{7} \mathrm{H}_{15}$ \\
\hline VP3.34 & $\mathrm{H}$ & $\mathrm{H}$ & $\mathrm{Me}$ & $-\mathrm{Ph}$ \\
\hline JAR1.56 & $\mathrm{H}$ & $\mathrm{Cl}$ & Et & $-\mathrm{C}_{7} \mathrm{H}_{15}$ \\
\hline
\end{tabular}

\begin{tabular}{|c|c|c|c|c|}
\hline $\begin{array}{l}\text { Comp } \\
\text { ID }\end{array}$ & $\mathbf{R}_{1}$ & $\mathbf{R}_{\mathbf{2}}$ & $\mathbf{R}_{\mathbf{3}}$ & $\mathbf{R}_{\mathbf{4}}$ \\
\hline JAR1.57 & $\mathrm{H}$ & $\mathrm{Cl}$ & $\mathrm{Me}$ & $-\mathrm{C}_{11} \mathrm{H}_{23}$ \\
\hline VP4.22 & $\mathrm{H}$ & $\mathrm{Cl}$ & $\mathrm{H}$ & $-\mathrm{C}_{11} \mathrm{H}_{23}$ \\
\hline JAR1.58 & $\mathrm{H}$ & $\mathrm{Cl}$ & $\mathrm{Me}$ & $-\mathrm{C}_{7} \mathrm{H}_{15}$ \\
\hline VP3.49 & $\mathrm{H}$ & $\mathrm{H}$ & $\mathrm{Me}$ & $-\mathrm{C}_{11} \mathrm{H}_{23}$ \\
\hline VP4.40 & $\mathrm{H}$ & $\mathrm{H}$ & $\mathrm{H}$ & $-\mathrm{C}_{7} \mathrm{H}_{15}$ \\
\hline VP3.38 & $\mathrm{H}$ & $\mathrm{H}$ & $\mathrm{Me}$ & $-\mathrm{CH}_{2} \mathrm{Ph}$ \\
\hline JAR1.51 & $\mathrm{Br}$ & $\mathrm{H}$ & $\mathrm{Me}$ & $-\mathrm{C}_{7} \mathrm{H}_{15}$ \\
\hline VP3.58 & $\mathrm{H}$ & $\mathrm{H}$ & Et & $-\mathrm{C}_{7} \mathrm{H}_{15}$ \\
\hline VP3.43 & $\mathrm{H}$ & $\mathrm{H}$ & $\mathrm{Me}$ & $-\mathrm{C}_{7} \mathrm{H}_{15}$ \\
\hline JAR1.40 & $\mathrm{Br}$ & $\mathrm{H}$ & Et & $-\mathrm{C}_{7} \mathrm{H}_{15}$ \\
\hline VP4.41 & $\mathrm{F}$ & $\mathrm{H}$ & $\mathrm{H}$ & $-\mathrm{C}_{7} \mathrm{H}_{15}$ \\
\hline VP3.50 & $\mathrm{H}$ & $\mathrm{H}$ & $\mathrm{H}$ & $-\mathrm{C}_{11} \mathrm{H}_{23}$ \\
\hline VP3.59 & $\mathrm{H}$ & $\mathrm{H}$ & Et & \\
\hline VP4.28 & $\mathrm{H}$ & $\mathrm{Cl}$ & $\mathrm{H}$ & \\
\hline VP3.52 & $\mathrm{H}$ & $\mathrm{H}$ & $\mathrm{Me}$ & \\
\hline VP3.37 & $\mathrm{H}$ & $\mathrm{H}$ & $\mathrm{Me}$ & $\mathrm{Me}$ \\
\hline JAR1.46 & $\mathrm{Cl}$ & $\mathrm{H}$ & $\mathrm{Me}$ & $-\mathrm{C}_{7} \mathrm{H}_{15}$ \\
\hline
\end{tabular}

${ }^{a}$ ARPE-19 MitoQC cells were treated with the compounds at a final concentration of $25 \mu \mathrm{M}$ for $24 \mathrm{~h}$. The $\mathrm{IC}_{50}$ values obtained from Palomo et al. $^{14}$

result from our first approach that compounds did not induce mitophagy by GSK3 inhibition, but the presence of a long aliphatic chain in their chemical structure was of utmost relevance for this biological property.

Once a long aliphatic chain was confirmed to be necessary to modulate mitophagy, we tested if the heterocycle was also required. To examine this, the ARPE-19 MitoQC cells were treated with the hydrazides bearing aliphatic chains of 11 and 7 carbon atoms. Neither of these two compounds induced mitophagy (Figure 7). This result confirms that the heterocycle, a quinolone scaffold, and a long aliphatic chain joined to the hydrazide moiety are needed to induce mitophagy.
Moreover, during the analysis of biological data and chemical structure, it is clear (Table 2) that substitution on the quinolone heterocycle has a significant impact on mitophagy induction. As a result, the substituents in heterocyclic nitrogen seem to have a key role in the biological response, displaying more mitophagyinducing capacity as lipophilicity increased. Mitophagy activity increased with the number of atoms present in the alkyl moiety $(\mathrm{Me}<\mathrm{Et}<\mathrm{iPr}<\mathrm{Bn})$ attached to the nitrogen aromatic atom, whereas the absence of substituents in this position did not induce it (see VP3.49 < VP07 < JAR2.16 < JAR2.3 compounds, Figure 6 and Table 2). In fact, compound JAR2.4, which has a benzyl moiety attached to the aromatic nitrogen, but an aliphatic chain of seven carbon atoms, is a good mitophagy inducer. 
$\mathrm{H}_{\mathrm{O}} \mathrm{N}^{\mathrm{N}} \mathrm{N}_{\mathrm{O}}^{\mathrm{N}}$
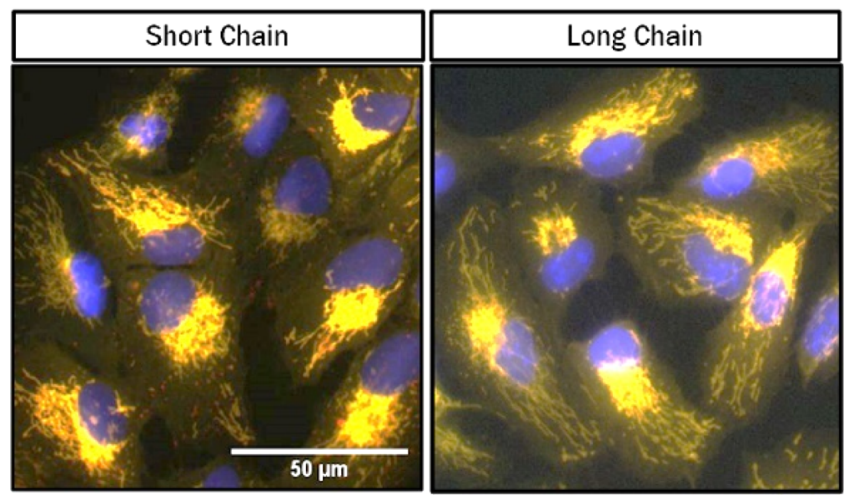

Figure 7. Representation of ARPE19 MitoQC cells treated with the hydrazide with short $\left(\mathrm{C}_{7} \mathrm{H}_{15}\right)$ and long $\left(\mathrm{C}_{11} \mathrm{H}_{23}\right)$ aliphatic chains. 50,000 cells $/ \mathrm{mL}$ were incubated with the hydrazides at $25 \mu \mathrm{M}$ for $24 \mathrm{~h}$. Scale bar $=50 \mu \mathrm{m}$.

Lastly, the halogenated substituent in the aromatic ring did not seem to play an important role in mitophagy induction, as both VP07 and JAR1.39, with and without a substituent in $\mathrm{R}_{1}$, are mitophagy inducers (Figure 6 and Table 2).

From these SAR studies, we could conclude that quinolones with an aliphatic chain of 11 carbon atoms and hydrophobic substituents in the aromatic nitrogen, such as JAR2.3, VP07, or JAR1.39, are more prone to induce mitophagy.

Taken together, these preliminary data highlight the promising potency of this structural family from our in-house library to enhance mitophagy as a therapeutic approach for PD and other pathologies in which mitophagy is decreased.

Proposed Mechanism of Action. Last, we attempted to speculate the mechanism of action by which the hits with the specific structure induced mitophagy. For this analysis, we based our hypothesis on the mechanism of action of other mitophagy regulators with a similar structure. Data have shown that both cardiolipin (CL) and ceramide induce mitophagy. ${ }^{29} \mathrm{CL}$ is a phospholipid present in the inner mitochondrial membrane. It has a polar head and four flexible acyl chains (Figure 8$)^{30}$ that can interact with several mitochondrial complexes. Under several stresses, such as harmful agents as rotenone or carbonyl cyanide $m$-chlorophenylhydrazone (CCCP), CL externalizes to the OMM, where it binds to LC3. ${ }^{29,31}$ The aliphatic chains of CL remain facing the mitochondrial matrix, while its polar head is exposed to interact with the LC3 $\mathrm{N}$-terminus. The LC3 Cterminus binds to the forming autophagosome, thus targeting cargo for mitophagy. ${ }^{32}$ Ceramide, on the other hand, is a sphingolipid synthetized by the enzyme CerS1 in the endoplasmic reticulum that localizes in the plasma membrane or mitochondria. ${ }^{33}$ In mitochondria, it can bind to the LC3 Nterminus, probably in a similar way as $\mathrm{CL}$, thus bridging mitochondria to the autophagosome. ${ }^{34}$

In addition, a recent work has analyzed the structure of metformin, a compound that activates the AMPK-ULK1 axis, triggering mitophagy. ${ }^{35}$ In that study, several metformin derivatives were synthetized by adding a triphenylphosphonium cationic moiety $\left(\mathrm{TPP}^{+}\right)$aliphatic chain to the compounds, bound by an aliphatic chain with different lengths. Data showed that the cellular uptake of metformin derivatives measured by LC-MS/MS increased with the length of the alkyl chain.<smiles>CCCCCCCCCCC(=O)NNC(=O)c1c(O)c2ccccc2n(CC)c1=O</smiles><smiles>[R14][Y10]#N</smiles>

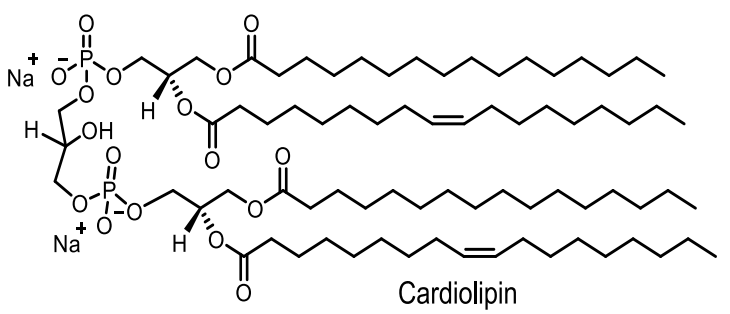<smiles>CCCCCCCCCC=CC(O)C(C)NC(=O)CCCCCCCCCCCCCCCCCCCCCCCCCCCCCC</smiles>

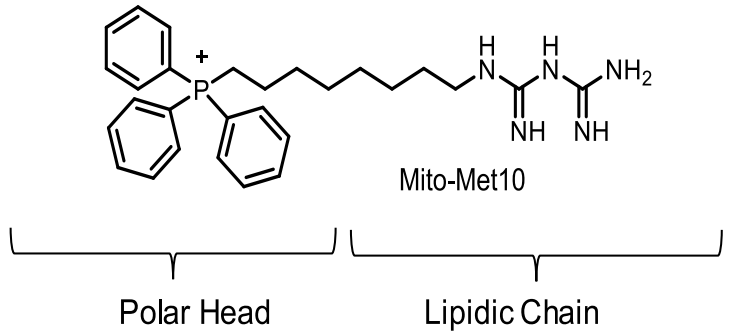

Figure 8. Structural comparison of the hits with other mitophagy modulators.

Together, Mito-Met ${ }_{10}$, with an alkyl chain of 10 carbons (Figure 8 ), was 1000 -fold more potent than metformin in the activation of $\mathrm{AMPK}^{36}$

Attending to the nature of our hits deciphered by SAR studies, their structural similarity with CL and ceramide, and the recent work done with metformin, one plausible hypothesis is that the VP07/JAR1.39 compound family may anchor the aliphatic chain in the OMM, with the polar head facing the cytoplasm where it could act to attract the LC $3 \mathrm{~N}$-terminus in a similar way as CL or ceramide. Finally, this mitophagy signal should be amplified by Pink1/Parkin signaling to produce mitochondrial degradation in the autophagosome.

Although further studies should be performed to confirm this hypothesis, it may be supported by our data, which showed an increase in LC3 punctae per cell and LC3 colocalizing with the mitochondria in cells treated with VP07 compared to the control (Figure 4B) and the fact that VP07-induced mitophagy was only observed in cells expressing Parkin (Figure 2).

Other potential mechanisms of action cannot be discarded, and given the presence of the acyl chain in both JAR1.39 and VP07 and the rather high concentration necessary for the effect, it might also be plausible that drugs may disrupt the OMM and indirectly promote autophagosome formation independent of a direct association of LC3 with the compounds. Moreover, the 

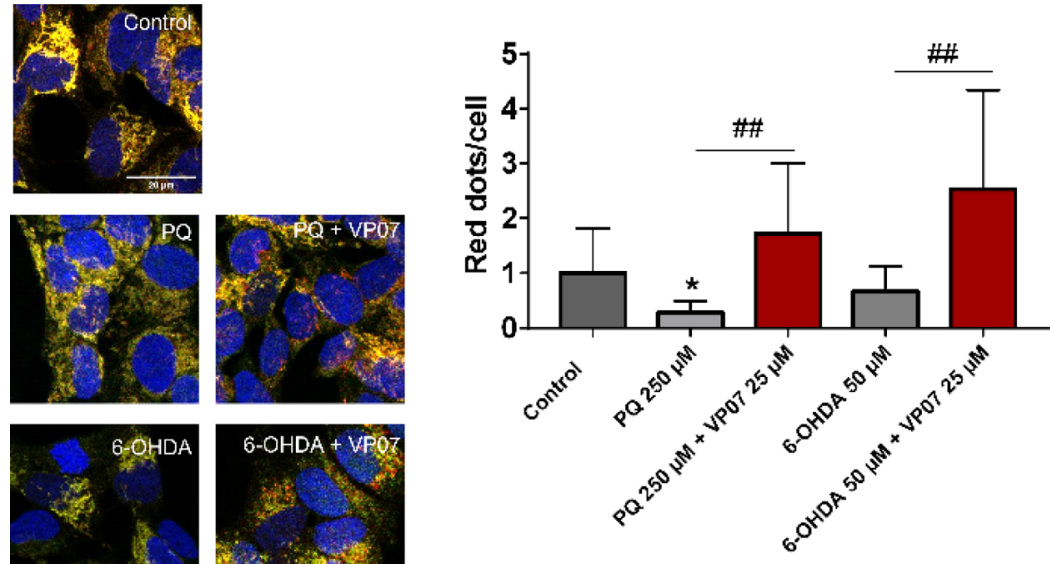

Figure 9. Therapeutic modulation of mitophagy by VP07 in a PD chemical model. The SH-SY5Y MitoQC cells ( 100,000 cells $/ \mathrm{mL})$ were pretreated with $25 \mu \mathrm{M}$ VP07 for $1 \mathrm{~h}$ and treated with $250 \mu \mathrm{M}$ PQ or $50 \mu \mathrm{M}$ 6-OHDA for $24 \mathrm{~h}$. The graph represents the mean \pm SD. Data were normalized to control. Significance was determined by the unpaired two tailed $t$-test, where $* p<0.05$, significantly different from control, and \#\#p<0.01, significantly different from PQ or 6-OHDA. Scale bar $=20 \mu \mathrm{m}$.

possibility that the compounds induce ceramide formation, which interacts with LC3, may also explain the mitophagy induction produced by these two compounds. Currently, ongoing studies will provide the correct hypothesis of the mechanism of action.

Therapeutic Potential of Mitophagy Inducers. It is common knowledge that defects in mitochondrial homeostasis are one of the hallmarks of neurodegeneration. Specifically, defective mitophagy and autophagy have been reported in postmortem brains of patients with $\mathrm{PD}$, as well as in in vitro and in vivo models. ${ }^{37}$ These, in addition to mitophagy-related gene mutations in $\mathrm{PD}$, underline the need for mitophagy enhancers in the treatment of this pathology. ${ }^{38,39}$ To evaluate the potential therapeutic effect of our compounds in defective mitophagy found in patients with PD, we used the human neuroblastoma cell line SH-SY5Y expressing the MitoQC reporter and treated it with paraquat (PQ) and 6-hydroxydopamine (6-OHDA). PQ is a toxin that causes oxidative stress and Parkinsonian lesions in some mouse strains and rats, ${ }^{40}$ inducing $\alpha$-synuclein aggregation in mice $^{41}$ and neurodegeneration. ${ }^{42}$

In comparison, 6-OHDA is a neurotoxin that accumulates in cells, leading to reactive oxygen species (ROS) production, oxidative stress, and the inhibition of complexes I and IV of the electron transport chain. ${ }^{43}$ The treatment of the SH-SY5Y cells with 6-OHDA increased the expression of PD-related genes, such as SNCA ( $\alpha$-synuclein), and decreased mitophagy-related genes, such as PINK1. ${ }^{44,45}$

As expected, PQ significantly reduced basal mitophagy compared to the control, confirming defective mitophagy in this model (Figure 9). Pretreatment with the hit VP07 prevented the decrease in mitophagy produced by $\mathrm{PQ}$, while a similar trend was observed with 6-OHDA treatment, showing the therapeutic potential of mitophagy inducers, and especially the role of VP07 in the rescue of the deficits observed in PD.

\section{CONCLUSIONS}

Although mitophagy is known to play a key role in mitochondria quality control being crucial in neuronal homeostasis, scientific advances are needed to decipher its role in neurological pathologies and propose new therapies for these unmet diseases. The lack of screening methods for drug discovery and chemical tools to advance its molecular biology may explain the current situation. We used two different biological systems (U2OSiMLS and ARPE-19 MitoQC cell lines) that allow for the phenotypic screening of a medium number of small compounds to discover new mitophagy modulators. We identified two structurally related compounds, JAR1.39 and VP07, based on hydrazine derivatives with a quinoline scaffold that induced mitophagy in vitro and may be used as valuable pharmacological probes for molecular studies of mitophagy in physiology and pathology. We propose that the mechanism of action of these new compounds may be similar to that of ceramide, anchoring these chemical probes to the mitochondrial membrane. Future studies will provide the therapeutic potential of these mitophagy inducers, confirming their relevance for the treatment of PD and other neurodegenerative conditions.

\section{EXPERIMENTAL PART}

Cell Lines. Human osteosarcoma U2OS cell line with stable inducible expression of the NIPSNAP internal mitochondria localization signal (iMLS) (NIPSNAP $1_{1-53}$ )-EGFP-mCherry (called U2OS iMLS cells $)^{14}$ and U2OS iMLS cells with stable expression of untagged Parkin ${ }^{41}$ were used for the screening. Both the cell lines were cultured in DMEM with glutamine supplemented with $10 \%$ FBS and Pen-Strep. The cells were selected with $100 \mu \mathrm{g} / \mathrm{mL}$ hygromycin and $5 \mu \mathrm{g} / \mathrm{mL}$ blasticidin. Additional $2 \mu \mathrm{g} / \mathrm{mL}$ puromycin was used for U2OS-iMLS + Parkin. To induce the expression of the mitophagy reporter, $500 \mu \mathrm{g} / \mathrm{mL}$ doxycycline was added for the last $24 \mathrm{~h}$.

Human retinal pigment epithelial cell line and neuroblastoma cell line stably expressing the mitophagy reporter mCherry-GFPFIS1 $1_{101-152}$ (ARPE-19 MitoQC and SH-SY5Y MitoQC, respectively) were cultured in DMEM/F12 (1:1) supplemented with $15 \%$ FBS, $1 \%$ glutamine $(2 \mathrm{mM})$, and $1 \%$ Pen-Strep $(0.5 \mathrm{mg} / \mathrm{mL}){ }^{20}$ In order to maintain in culture, only the cells with the reporter, 800 and $500 \mu \mathrm{g} / \mathrm{mL}$ hygromycin were used for ARPE-19 and SH-SY5Y cell lines, respectively.

Compound Preparation. All the compounds were prepared with a stock concentration of $25 \mathrm{mM}$ in DMSO. The final \% of DMSO in the cell culture was not higher than 0.1\%. FCCP (Sigma, C2920) was used at $5 \mu \mathrm{M}$, and bafilomycin A1 (Enzo Life Sciences, BML-CM110) was used at $100 \mathrm{nM}$. PQ (Sigma, 856177-1G) was prepared in PBS $1 \times$ at 50 $\mathrm{mM}$, and 6-OHDA (Sigma, H4381) was prepared in water at $50 \mathrm{mM}$.

Mitophagy Assay. U2OS-iMLS \pm Parkin and ARPE-19 MitoQC cells were seeded at a final concentration of 50,000 cells $/ \mathrm{mL}$ in a 96 -well plate and in crystals in a 24-well plate, respectively. In the case of the 
SH-SY5Y MitoQC cells, 100,000 cells/mL were seeded in a 24 -well plate. The next day, the cells were treated as indicated. In the case of U2OS-iMLS, $500 \mu \mathrm{g} / \mathrm{mL}$ doxycycline was added to medium to induce the expression of the reporter. After $24 \mathrm{~h}$, the cells were fixed with $3.7 \%$ $200 \mathrm{mM} \mathrm{N}$-(2-hydroxyethyl)piperazine- $\mathrm{N}^{\prime}$-ethanesulfonic acid (PFA) Hepes and incubated with Hoechst (Invitrogen, H1399) to stain the nuclei. The U2OS cells were maintained in the plates in PBS until images were acquired. The ARPE-19 MitoQC cells were seeded in crystals and incubated with DAPI (Sigma-Aldrich-2D9542) to stain the nuclei. Then, the crystals were mounted over slides with ProLong Diamond Antifade Mountant (Thermo, P36961). The slides were kept for $24 \mathrm{~h}$ at $\mathrm{RT}$ and then at $4{ }^{\circ} \mathrm{C}$ until images were acquired.

Image Acquisition. Images of the U2OS iMLS cells in 96-well plates were obtained under an ImageXpress Micro Confocal microscope (Molecular Devices), placed in the Advanced Light Microscopy Facility at Gaustad (University of Oslo, Norway). Six images per well were automatically taken at $20 \times$ in order to quantify around 1000 cells per condition.

Images of the ARPE-19 MitoQC and SH-SY5Y MitoQC cells in 24well plates were obtained with an AF6000 LX widefield multidimensional microscopy system and CLSMLEICA TCS SP8 STED 3X placed in the confocal laser and multidimensional microscopy in vivo facility at CIB Margarita Salas (Madrid, Spain). Five to six images were manually taken at $40 \times$ and $63 \times$, respectively, in order to have around 100 cells per coverslip.

Western Blotting. A total of 200,000 cells $/ \mathrm{mL}$ were seeded in a 6well plate. After $24 \mathrm{~h}$, the cells were treated as indicated. Proteins were extracted with lysis buffer [50 mM Tris-HCl pH 6.8, $10 \%$ glycerol (v/v) and $2 \%$ sodium dodecyl sulfate $(\mathrm{w} / \mathrm{v})$, in distilled water] with protease inhibitors $1 \times$ (Sigma, P8783) and phosphatase inhibitors [1 mM sodium orthovanadate (Sigma, S6508), $1 \mathrm{mM}$ sodium fluoride (Sigma, 201154), and $5 \mathrm{mM}$ sodium pyrophosphate decahydrate (Sigma, 221368)]. The proteins were scrapped and transferred to a tube. The samples were heated at $95^{\circ} \mathrm{C}$ for $15 \mathrm{~min}$ and spun and stored at $-20^{\circ} \mathrm{C}$ until used. To quantify the proteins, a bicinchoninic acid protein assay kit (Pierce, 23227) was used, and $12 \mu \mathrm{g}$ of proteins was loaded with 10 $\mathrm{mM}$ dithiothreitol and $0.005 \%$ bromophenol blue in Criterion TGX Precast Midi Protein gels (BioRad, 5671124) and transferred to polyvinylidene fluoride membranes (BioRad, 170-4157) activated with 100\% methanol (Panreac, 131091.1214) for $2 \mathrm{~min}$. The transfers were done with Trans-Blot Turbo Transfer (BioRad) for $14 \mathrm{~min}$ (two waves of $7 \mathrm{~min}$ each) at $25 \mathrm{~V}$. After the transfers, protein bands were detected with Ponceau Red (Sigma, 78376). The membranes were blocked with blocking buffer [TBS, 1\% Tween-20 (TBS-T), and 5\% BSA] for $1 \mathrm{~h} / \mathrm{RT}$ before incubation overnight at $4{ }^{\circ} \mathrm{C}$ with primary antibodies in blocking buffer. The membranes were washed $3 \times 10 \mathrm{~min}$ with TBS-T before secondary antibody incubation (in blocking buffer for $1 \mathrm{~h}$ ).The membranes were also washed $3 \times 10 \mathrm{~min}$ with TBS-T before membrane imaging.

Antibodies for the Western Blot. Primary antibody targeting TOMM20 (1:1000, rabbit, sc-11415) was obtained from Santa Cruz Biotechnologies. TIMM23 (1:1000, mouse, 611222) was obtained from BD Biosciences. GAPDH (1:1000, mouse, ab8245) was purchased from Abcam. The signal was amplified with anti-rabbit and anti-mouse secondary antibodies conjugated with peroxidase.

Citrate Synthase Assay. A total of 200,000 cells $/ \mathrm{mL}$ were seeded in a 6-well plate. After $24 \mathrm{~h}$, the cells were treated as indicated. Then, the cells were washed with cold PBS $1 \times$. The cells were resuspended in NP40 lysis buffer in water ( $150 \mathrm{mM} \mathrm{NaCl}, 1 \% \mathrm{NP}-40$, and $50 \mathrm{mM}$ Tris $\mathrm{pH}$ 8), rotated in a cold room for $30 \mathrm{~min}$, and centrifuged at $13,000 \mathrm{~g}$ for 20 min in cold. Then, the supernatant was collected and stored at $-20{ }^{\circ} \mathrm{C}$ until used.

Citrate synthase activity was determined by incubating $5 \mu \mathrm{L}$ of proteins with $995 \mu \mathrm{L}$ of $100 \mathrm{mM}$ Tris pH 8, 0.1\% Triton, $0.1 \mathrm{mM}$ acetyl-

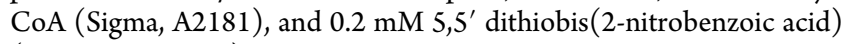
(Sigma D8130-1G). $198 \mu \mathrm{L}$ of the mix was pipetted in triplicates on a 96-well plate, and $2 \mu \mathrm{L}$ of oxaloacetate (Sigma O4126-1G) was added to the sample wells. Absorbance was measured at $412 \mathrm{~nm}$ every $30 \mathrm{~s}$ for up to $60 \mathrm{~min}$ at $30{ }^{\circ} \mathrm{C}$. The results were normalized to protein concentration.
Immunostaining. The U2OS-iMLS cells expressing Parkin were seeded at a final concentration of 50,000 cells $/ \mathrm{mL}$ in a $96-w e l l$ plate. The next day, the cells were treated as indicated, and $500 \mu \mathrm{g} / \mathrm{mL}$ doxycycline was added to medium to induce the expression of the reporter. After $24 \mathrm{~h}$, the cells were fixed with 3.7\% $200 \mathrm{mM}$ PFA Hepes and incubated with Hoechst (Invitrogen, H1399) to stain the nuclei. The cells were washed with $0.2 \%$ NP-40 to permeabilize the cells. Then, the cells were washed with PBS $1 \%$ BSA and incubated with the primary antibody (LC3; 1:500, MBL-PM036) for $1 \mathrm{~h}$ at $37^{\circ} \mathrm{C}$. After washing steps, the cells were incubated with the secondary antibody Rabbit DyLight 649 (1:500) for $30 \mathrm{~min}$ at RT. Finally, the cells were kept in PBS until imaged.

Image Analysis. Image analysis was done with CellProfiler. ${ }^{18}$ In order to identify red-only structures per cell segmentation of nuclei, cells and mitochondrial network were performed. Mitochondrial structures were further filtered as "yellow" or "red-only" based on the ratio between their EGFP and mCherry integrated intensities. The final number of red-only structures per cell was used as a mitophagy rate readout. Later, this pipeline was modified in order to analyze mitophagy in cells seeded in 24-well plates.

For the mitochondrial morphology study, segmentation of mCherry structures was done and the mean area of each mitochondrial fragment per image was used as a final readout..

\section{ASSOCIATED CONTENT}

\section{Supporting Information}

The Supporting Information is available free of charge at https://pubs.acs.org/doi/10.1021/acschemneuro.1c00529.

Structure of compounds preselected from the MBC library for mitophagy phenotypic screening in U2OSiMLS cells (PDF)

\section{AUTHOR INFORMATION}

\section{Corresponding Authors}

Ana Martinez - Centro de Investigaciones Biologicas Margarita Salas-CSIC, 28040 Madrid, Spain; Centro de Investigacion Biomedica en Red en Enfermedades Neurodegenerativas (CIBERNED), Instituto de Salud Carlos III, 28031 Madrid, Spain; (1) orcid.org/0000-0002-2707-8110; Email: ana.martinez@csic.es

Patricia Boya - Centro de Investigaciones Biologicas Margarita Salas-CSIC, 28040 Madrid, Spain; Email: pboya@cib.csic.es

\section{Authors}

Inés Maestro - Centro de Investigaciones Biologicas Margarita Salas-CSIC, 28040 Madrid, Spain; Centro de Investigacion Biomedica en Red en Enfermedades Neurodegenerativas (CIBERNED), Instituto de Salud Carlos III, 28031 Madrid, Spain

Laura R. de la Ballina - Department of Molecular Medicine, Institute of Basic Medical Sciences, Faculty of Medicine, University of Oslo, 0372 Oslo, Norway; Centre for Cancer Cell Reprogramming, Institute of Clinical Medicine, Faculty of Medicine, University of Oslo, 0450 Oslo, Norway

Anne Simonsen - Department of Molecular Medicine, Institute of Basic Medical Sciences, Faculty of Medicine, University of Oslo, 0372 Oslo, Norway; Centre for Cancer Cell Reprogramming, Institute of Clinical Medicine, Faculty of Medicine, University of Oslo, 0450 Oslo, Norway

Complete contact information is available at:

https://pubs.acs.org/10.1021/acschemneuro.1c00529 


\section{Author Contributions}

I.M. performed the experiments and wrote the first draft of this manuscript; L.R.d.l.B. participated in the experimental mitophagy screening; A.S. designed and supervised the mitophagy screening; and A.M. and P.B. conceived, designed, and supervised this study. All authors analyzed the data, reviewed/ edited the drafts, and have given approval to the final version of the manuscript.

\section{Notes}

The authors declare no competing financial interest.

\section{ACKNOWLEDGMENTS}

This research was supported by the H2020-MSCA-ITN-2017 (grant no. 765912) DRIVE project, Spain's Ministerio de Ciencia e Innovación (grant nos. PGC2018-098557-B-I00 to P.B. and PID2019-105600RB-I00 to A.M.), FRIPRO (project no. 221831 to A.S.), and the Research Council of Norway through its Centres of Excellence funding scheme (project no. 262652). We thank M. Teresa Seisdedos and Gema Elvira at the Confocal Microscopy facility for their help with the image acquisition and Ian Ganley for kindly providing ARPE-10 and SH-SY5Y MitoQC.

\section{ABBREVIATIONS}

$\mathrm{AD}$, Alzheimer's disease; $\mathrm{CL}$, cardiolipin; CCCP, carbonyl cyanide $m$-chlorophenylhydrazone; CNS, central nervous system; DFP, deferiprone; EGFP, green fluorescent protein; FCCP, carbonilcianuro-p-trifluorometoxifenilhidrazona; GSK3, glycogen synthase kinase 3; iMLS, internal mitochondrial localization signal; LC3, microtubule-associated protein 1A/ 1B-light chain 3; 6-OHDA, 6-hydroxydopamine; OMM, outer mitochondrial membrane; $\mathrm{PD}$, Parkinson's disease; $\mathrm{PQ}$, paraquat; ROS, radical oxygen species; SAR, structure-activity relationship

\section{REFERENCES}

(1) Onishi, M.; Yamano, K.; Sato, M.; Matsuda, N.; Okamoto, K. Molecular mechanisms and physiological functions of mitophagy. EMBO J. 2021, 40, No. e104705.

(2) Lamark, T.; Johansen, T. Mechanisms of Selective Autophagy. Annu. Rev. Cell Dev. Biol. 2021, 37, 143.

(3) Ng, M. Y. W.; Wai, T.; Simonsen, A. Quality control of the mitochondrion. Dev. Cell 2021, 56, 881-905.

(4) McWilliams, T. G.; Barini, E.; Pohjolan-Pirhonen, R.; Brooks, S. P.; Singh, F.; Burel, S.; Balk, K.; Kumar, A.; Montava-Garriga, L.; Prescott, A. R.; Hassoun, S. M.; Mouton-Liger, F.; Ball, G.; Hills, R.; Knebel, A.; Ulusoy, A.; Di Monte, D. A.; Tamjar, J.; Antico, O.; Fears, K.; Smith, L.; Brambilla, R.; Palin, E.; Valori, M.; Eerola-Rautio, J.; Tienari, P.; Corti, O.; Dunnett, S. B.; Ganley, I. G.; Suomalainen, A.; Muqit, M. M. K. Phosphorylation of Parkin at serine 65 is essential for its activation in vivo. Open Biol. 2018, 8, 180108.

(5) Um, J.-H.; Yun, J. Emerging role of mitophagy in human diseases and physiology. BMB Rep. 2017, 50, 299-307.

(6) Killackey, S. A.; Philpott, D. J.; Girardin, S. E. Mitophagy pathways in health and disease. J. Cell Biol. 2020, 219, No. e202004029.

(7) Sun, N.; Yun, J.; Liu, J.; Malide, D.; Liu, C.; Rovira, II; Holmström, K. M.; Fergusson, M. M.; Yoo, Y. H.; Combs, C. A.; Finkel, T. Measuring In Vivo Mitophagy. Mol. Cell 2015, 60, 685-696.

(8) Madruga, E.; Maestro, I.; Martinez, A. Mitophagy Modulation, a New Player in the Race against ALS. Int. J. Mol. Sci. 2021, 22, 740.

(9) Doxaki, C.; Palikaras, K. Neuronal Mitophagy: Friend or Foe? Front. Cell Dev. Biol. 2020, 8, 611938.

(10) Aman, Y.; Ryan, B.; Torsetnes, S. B.; Knapskog, A.-B.; Watne, L. O.; McEwan, W. A.; Fang, E. F. Enhancing mitophagy as a therapeutic approach for neurodegenerative diseases. Int. Rev. Neurobiol. 2020, 155, 169-202.

(11) Mauro-Lizcano, M.; Esteban-Martínez, L.; Seco, E.; SerranoPuebla, A.; Garcia-Ledo, L.; Figueiredo-Pereira, C.; Vieira, H. L. A.; Boya, P. New method to assess mitophagy flux by flow cytometry. Autophagy 2015, 11, 833-843.

(12) Klionsky, D. J.; et al. Guidelines for the use and interpretation of assays for monitoring autophagy (4th edition)(1). Autophagy 2021, 17, $1-382$.

(13) Sebastián-Pérez, V.; Roca, C.; Awale, M.; Reymond, J.-L.; Martinez, A.; Gil, C.; Campillo, N. E. Medicinal and Biological Chemistry (MBC) Library: An Efficient Source of New Hits. J. Chem. Inf. Model. 2017, 57, 2143-2151.

(14) Palomo, V.; Perez, D. I.; Roca, C.; Anderson, C.; RodríguezMuela, N.; Perez, C.; Morales-Garcia, J. A.; Reyes, J. A.; Campillo, N. E.; Perez-Castillo, A. M.; Rubin, L. L.; Timchenko, L.; Gil, C.; Martinez, A. Subtly Modulating Glycogen Synthase Kinase 3 beta: Allosteric Inhibitor Development and Their Potential for the Treatment of Chronic Diseases. J. Med. Chem. 2017, 60, 4983-5001.

(15) Princely Abudu, Y.; Pankiv, S.; Mathai, B. J.; Håkon Lystad, A.; Bindesbøll, C.; Brenne, H. B.; Yoke Wui Ng, M.; Thiede, B.; Yamamoto, A.; Mutugi Nthiga, T.; Lamark, T.; Esguerra, C. V.; Johansen, T.; Simonsen, A. NIPSNAP1 and NIPSNAP2 Act as "Eat Me" Signals for Mitophagy. Dev. Cell 2019, 49, 509-525.

(16) Tang, M. Y.; Vranas, M.; Krahn, A. I.; Pundlik, S.; Trempe, J. F.; Fon, E. A. Structure-guided mutagenesis reveals a hierarchical mechanism of Parkin activation. Nat. Commun. 2017, 8, 14697.

(17) Palikaras, K.; Princz, A.; Tavernarakis, N. Mitophagy Modulators. Encycl. Biomed. Gerontol. 2020, 433-446.

(18) Yoshimori, T.; Yamamoto, A.; Moriyama, Y.; Futai, M.; Tashiro, Y. Bafilomycin Al, a specific inhibitor of vacuolar-type $\mathrm{H}(+)$-ATPase, inhibits acidification and protein degradation in lysosomes of cultured cells. J. Biol. Chem. 1991, 266, 17707-17712.

(19) Carpenter, A. E.; Jones, T. R.; Lamprecht, M. R.; Clarke, C.; Kang, I.; Friman, O.; Guertin, D. A.; Chang, J.; Lindquist, R. A.; Moffat, J.; Golland, P.; Sabatini, D. M. CellProfiler: image analysis software for identifying and quantifying cell phenotypes. Genome Biol. 2006, 7, R100.

(20) Huang, C.; Lu, H.; Xu, J.; Yu, H.; Wang, X.; Zhang, X. Protective roles of autophagy in retinal pigment epithelium under high glucose condition via regulating PINK1/Parkin pathway and BNIP3L. Biol. Res. 2018, 51, 22.

(21) Allen, G. F. G.; Toth, R.; James, J.; Ganley, I. G. Loss of iron triggers PINK1/Parkin-independent mitophagy. EMBO Rep. 2013, 14, $1127-1135$

(22) Ryu, H. Y.; Kim, L. E.; Jeong, H.; Yeo, B. K.; Lee, J.-W.; Nam, H.; Ha, S.; An, H.-K.; Park, H.; Jung, S.; Chung, K. M.; Kim, J.; Lee, B.-H.; Cheong, H.; Kim, E.-K.; Yu, S.-W. GSK3B induces autophagy by phosphorylating ULK1. Exp. Mol. Med. 2021, 53, 369-383.

(23) Rippin, I.; Eldar-Finkelman, H. Mechanisms and Therapeutic Implications of GSK-3 in Treating Neurodegeneration. Cells 2021, 10, 262.

(24) Soutar, M. P. M.; Kempthorne, L.; Miyakawa, S.; Annuario, E.; Melandri, D.; Harley, J.; O’Sullivan, G. A.; Wray, S.; Hancock, D. C.; Cookson, M. R.; Downward, J.; Carlton, M.; Plun-Favreau, H. AKT signalling selectively regulates PINK1 mitophagy in SHSY5Y cells and human iPSC-derived neurons. Sci. Rep. 2018, 8, 8855.

(25) Swerdlow, N. S.; Wilkins, H. M. Mitophagy and the Brain. Int. J. Mol. Sci. 2020, 21, 9661.

(26) Florian, S.; Hümmer, S.; Catarinella, M.; Mayer, T. U. Chemical genetics: reshaping biology through chemistry. HFSP J. 2007, 1, 104114.

(27) Palomo, V.; Perez, D. I.; Perez, C.; Morales-Garcia, J. A.; Soteras, I.; Alonso-Gil, S.; Encinas, A.; Castro, A.; Campillo, N. E.; PerezCastillo, A.; Gil, C.; Martinez, A. 5-imino-1,2,4-thiadiazoles: first small molecules as substrate competitive inhibitors of glycogen synthase kinase 3. J. Med. Chem. 2012, 55, 1645-1661.

(28) Martinez, A.; Alonso, M.; Castro, A.; Pérez, C.; Moreno, F. J. First non-ATP competitive glycogen synthase kinase 3 beta (GSK-3beta) 
inhibitors: thiadiazolidinones (TDZD) as potential drugs for the treatment of Alzheimer's disease. J. Med. Chem. 2002, 45, 1292-1299.

(29) Terešak, P.; Lapao, A.; Subic, N.; Boya, P.; Elazar, Z.; Simonsen, A. Regulation of PRKN-independent mitophagy. Autophagy 2021, DOI: $10.1080 / 15548627.2021 .1888244$.

(30) Li, X.-X.; Tsoi, B.; Li, Y.-F.; Kurihara, H.; He, R.-R. Cardiolipin and its different properties in mitophagy and apoptosis. J. Histochem. Cytochem. 2015, 63, 301-311.

(31) Chu, C. T.; Ji, J.; Dagda, R. K.; Jiang, J. F.; Tyurina, Y. Y.; Kapralov, A. A.; Tyurin, V. A.; Yanamala, N.; Shrivastava, I. H.; Mohammadyani, D.; Qiang Wang, K. Z.; Zhu, J.; Klein-Seetharaman, J.; Balasubramanian, K.; Amoscato, A. A.; Borisenko, G.; Huang, Z.; Gusdon, A. M.; Cheikhi, A.; Steer, E. K.; Wang, R.; Baty, C.; Watkins, S.; Bahar, I.; Bayır, H.; Kagan, V. E. Cardiolipin externalization to the outer mitochondrial membrane acts as an elimination signal for mitophagy in neuronal cells. Nat. Cell Biol. 2013, 15, 1197-1205.

(32) Antón, Z.; Landajuela, A.; Hervás, J. H.; Montes, L. R.; Hernández-Tiedra, S.; Velasco, G.; Goñi, F. M.; Alonso, A. Human Atg8-cardiolipin interactions in mitophagy: Specific properties of LC3B, GABARAPL2 and GABARAP. Autophagy 2016, 12, 23862403.

(33) Scarlatti, F.; Bauvy, C.; Ventruti, A.; Sala, G.; Cluzeaud, F.; Vandewalle, A.; Ghidoni, R.; Codogno, P. Ceramide-mediated macroautophagy involves inhibition of protein kinase $B$ and upregulation of beclin 1. J. Biol. Chem. 2004, 279, 18384-18391.

(34) Dany, M.; Ogretmen, B. Ceramide induced mitophagy and tumor suppression. Biochim. Biophys. Acta 2015, 1853, 2834-2845.

(35) Bhansali, S.; Bhansali, A.; Dhawan, V. Metformin promotes mitophagy in mononuclear cells: a potential in vitro model for unraveling metformin's mechanism of action. Ann. N. Y. Acad. Sci. 2020, 1463, 23-36.

(36) Cheng, G.; Zielonka, J.; Ouari, O.; Lopez, M.; McAllister, D.; Boyle, K.; Barrios, C. S.; Weber, J. J.; Johnson, B. D.; Hardy, M.; Dwinell, M. B.; Kalyanaraman, B. Mitochondria-Targeted Analogues of Metformin Exhibit Enhanced Antiproliferative and Radiosensitizing Effects in Pancreatic Cancer Cells. Cancer Res. 2016, 76, 3904-3915.

(37) Moors, T. E.; Hoozemans, J. J. M.; Ingrassia, A.; Beccari, T.; Parnetti, L.; Chartier-Harlin, M.-C.; van de Berg, W. D. J. Therapeutic potential of autophagy-enhancing agents in Parkinson's disease. Mol. Neurodegener. 2017, 12, 11.

(38) Dernie, F. Mitophagy in Parkinson's disease: From pathogenesis to treatment target. Neurochem. Int. 2020, 138, 104756.

(39) Liu, J.; Liu, W.; Li, R.; Yang, H. Mitophagy in Parkinson's Disease: From Pathogenesis to Treatment. Cells 2019, 8, 712.

(40) Berry, C.; La Vecchia, C.; Nicotera, P. Paraquat and Parkinson's disease. Cell Death Differ. 2010, 17, 1115-1125.

(41) Wills, J.; Credle, J.; Oaks, A. W.; Duka, V.; Lee, J.-H.; Jones, J.; Sidhu, A. Paraquat, but not maneb, induces synucleinopathy and tauopathy in striata of mice through inhibition of proteasomal and autophagic pathways. PLoS One 2012, 7, No. e30745.

(42) Huang, C.-Y.; Sivalingam, K.; Shibu, M. A.; Liao, P. H.; Ho, T. J.; Kuo, W. W.; Chen, R. J.; Day, C. H.; Viswanadha, V. P.; Ju, D. T. Induction of Autophagy by Vasicinone Protects Neural Cells from Mitochondrial Dysfunction and Attenuates Paraquat-Mediated Parkinson's Disease Associated alpha-Synuclein Levels. Nutrients 2020, 12, 1707.

(43) Xicoy, H.; Wieringa, B.; Martens, G. J. M. The SH-SY5Y cell line in Parkinson's disease research: a systematic review. Mol. Neurodegener. 2017, 12, 10.

(44) Yiğit, E. N.; Sönmez, E.; Sögüut, M. S.; Çakır, T.; Kurnaz, I. A. Validation of an In-Vitro Parkinson's Disease Model for the Study of Neuroprotection. Proceedings 2018, 2, 1559.

(45) Munson, M. J.; Mathai, B. J.; Ng, M. Y. W.; Trachsel-Moncho, L.; de la Ballina, L. R.; Schultz, S. W.; Aman, Y.; Lystad, A. H.; Singh, S.; Singh, S.; Wesche, J.; Fang, E. F.; Simonsen, A. GAK and PRKCD are positive regulators of PRKN-independent mitophagy. Nat. Commun. 2021, 12, 6101 . 